\title{
A Multidisciplinary Work-Related Low Back Pain Predictor Questionnaire: Psychometric Evaluation of Iranian Patient-Care Workers
}

\author{
Shojaei Sarallah ${ }^{1}$, Tavafian Sedigheh Sadat ${ }^{1}$, Ahmad Reza Jamshidi ${ }^{2}$, Wagner Joan ${ }^{3}$ \\ ${ }^{1}$ Department of Health Education, Faculty of Medical Sciences, Tarbiat Modares University, Tehran, Iran \\ ${ }^{2}$ Rheumatology Research Center, Tehran University of Medical Sciences, Tehran, Iran \\ ${ }^{3}$ Department of Philosophy (Rehabilitation Science), University of Alberta, Edmonton, AB, Canada
}

\begin{abstract}
Study Design: Psychometric evaluation design.
Purpose: Psychometric evaluation of a multidisciplinary work-related low back pain predictor questionnaire (MWRLBPPO) of Iranians patient-care workers based on the social cognitive theory.

Overview of Literature: Healthcare is one of the professions in which work-related musculoskeletal disorders are prevalent. The chronic low back pain experienced by patient caregivers can negatively impact their professional performance, and patient handling in a hospital is the main cause of low back pain in this population.

Methods: This was a cross-sectional study carried out in Qom, Iran from July 2014 to November 2014. A MWRLBPPO based on nine concepts of the social cognitive theory and existing literature regarding chronic low back pain was developed. Ten patient-care workers first completed the questionnaire as a pilot test, allowing the ambiguities of the instrument to be resolved. Exploratory factor analysis was used to confirm construct validity. This questionnaire was distributed among 452 patient-care workers in hospitals located in different geographically areas in 0om, Iran. Cronbach's Alpha was calculated to assess reliability.

Results: In all, 452 caregivers of patients with mean age of 37.71 (standard deviation=8.3) years participated in the study. An exploratory factor analysis loaded seven concepts of self-efficacy, knowledge, outcome perception, self-control, emotional coping, and selfefficacy in overcoming impediments and challenges in the environment. All concepts were jointly accounted for $50.08 \%$ of variance of behavior change. The Cronbach's alpha coefficient showed favorable internal consistency (alpha $=0.83$ ), and test-retest of the scale with 2-week intervals indicated an appropriate stability for the MWRLBPPO.

Conclusions: The MWRLBPPQ is a reliable and valid theory-based instrument that can be used to predict factors influencing workrelated low back pain among workers who lift and transfer patients in hospitals.
\end{abstract}

Keywords: Work-related low back pain; Patient-care workers; Social cognitive theory; Multidisciplinary; Questionnaire development

\section{Introduction}

Musculoskeletal disorders (MSD) make up a significant portion of occupational-related injuries and disabilities within the nursing profession [1]. Risk factors are known to include workplace activities such as manual handling,

\footnotetext{
Received Oct 7, 2015; Revised Nov 5, 2015; Accepted Nov 5, 2015

Corresponding author: Tavaian Sedigheh Sadat

Department of Health Education, Faculty of Medical Sciences, Tarbiat Modares University, Tehran, Iran

E-mail:tavafian@modares.ac.ir
} 
heavy lifting, strenuous tasks and the overall work environment $[2,3]$. Work musculoskeletal disorders (WMSDs) are common among healthcare workers, with the nursing population constituting about $33 \%$ of the hospital workforce at particularly high risk and accounting for $60 \%$ of the reported occupational injuries [4]. Low back pain is common among nurses $[5,6]$, and the pain frequently experienced by nurses undermines psychological health and reduces professional performance. A study on this subject showed that low back pain is the most common reason for nurses to change jobs [7], and another study showed that $11 \%$ of nurses do indeed quit their jobs because of low back pain [8]. Often patient-care workers are responsible for the task of patient handling in a hospital, and besides lifting patients and transferring patients in and out of bed and from the floor, also routinely perform activities that require lifting additional heavy loads and using difficult postures. Therefore, the design and implementation of health enhancement programs are essential for this group of people.

Social cognitive theory (SCT) provides a comprehensive and well-supported conceptual framework for understanding the factors that influence human behavior and the processes through which learning occurs. It offers insight into a wide variety of health-related issues, and its greatest contribution has come from the application of SCT to the design of interventions to meet important practical challenges in medicine and public health [9]. As part of the premise of SCT, behavior can be changed through new learning experiences, new guidance in the adjustment of perceptions, and support for the development of capacities [10]. As such, SCT was selected to address the needs in health enhancement programs. SCT was first known as the social learning theory [11], and it was renamed when concepts from cognitive psychology were integrated to the theory to accommodate the growing understanding of human information processing capacities and biases that influence learning from experience, observation, and symbolic communication [12]. This theory focuses on people's potential to alter and construct environments to suit purposes they devise for themselves and attracts the attention of health educators because it provides an explanation and predicts behaviors in terms of the interaction between the individual, the behavior, and the environment.

Because of the difficulty of the nursing tasks, issues having to do with the working environment and individual psychological determinants on low back pain behavior are important and need to be addressed. Although many researchers have studied low back pain among hospital nurses, most have ignored patient-care workers, even though most patient lifting and transferring task in hospital are performed by this group. The main objective of this study was to evaluate the multidisciplinary work-related low back pain predictor questionnaire (MWRLBPPQ) among Iranians patient-care providers.

\section{Materials and Methods}

This was a cross-sectional study for psychometric evaluation of the MWRLBPPQ designed for Iranians workers assigned with the tasks of lifting and transferring patients in hospitals. This instrument was developed based on the SCT and the existing literature on work-related low back pain $[10,13]$. Convenience sampling was used to select the patient-care workers who met the following inclusion criteria: having been care workers for at least one year, being aged $\geq 18$ years, and suffering from chronic low back pain (CLBP) due to mechanical forces for more than 90 days. However patient-care workers who reported suffering from infection in their vertebra, having myofascial back pain, spinal stenosis or recent vertebral fracture, or a history of surgery on the vertebra during the past two years of the study initiation were not entered into the study. Furthermore, all care workers who reported severe back pain or were unwilling to participate in the study were not part of the study. In this study because of low literacy levels of the target population, some of the participants completed the questionnaire as a pilot run to facilitate resolution of ambiguities. Ten patient-care providers from different units were selected for completing the questionnaire. The expert panel involved in similar surveys consisted of ten specialists that included two neurosurgeons, one rheumatologist, one epidemiologist, and three nursing teachers. Three health education experts checked all the survey items and inserted their recommendations into the questionnaire, and the content validity was established. In addition, there was an effort to have the questionnaire language be simple and easy to be understood for the participants.

The validity of the instrument concepts was determined by a sample of 452 people who lift and transfer patients in hospital. This sample consisted of people who met the inclusion criteria for the study. The two-section question- 
naire, consisting of 17 demographic questions and 50 questions related to the nine concepts of the SCT. Each concept included five to six questions. The demographic questions dealt with socio-economic characteristics, employment/working status, low back pain characteristics, and healthy preventive behaviors due to back pain.

\section{Data analysis}

Several statistical analyses were performed to assess the psychometric properties of the questionnaire. The construct validity of the questionnaire was examined using exploratory factor analyses (EFA) $[14,15]$. A principal component analysis with Varimax rotation was performed to extract underlying factors. Factor loadings equal or greater than 0.5 were considered appropriate [16]. Eigenvalues above 1 and scree plots were used for determining the number of statements $[17,18]$. The Kaiser-MeyerOlkin measure and Bartlett's test of sphericity were used to assess the appropriateness of the sample for the factor analysis $[17,18]$.

Internal consistency of the instrument was evaluated by the Cronbach's alpha coefficient, once for the entire questionnaire, and once for each concept. The Cronbach's alpha coefficient of 0.7 or above was thought to be satisfactory $[14,19]$. In addition, we used test-retest to examine the instrument's stability by calculating intraclass correlation coefficient (ICC) with a sub-sample of nursing $(n=28)$ who completed the questionnaire twice with an interval of 2 weeks [20]. The acceptable value for ICC, was considered 0.4 or above [20]. All the statistical analyses and EFA were performed using the SPSS ver. 16.0 (SPSS Inc., Chicago, IL, USA) [21].

\section{Main study and data collection}

A multistage cluster sampling was applied. Six hospitals affiliated with Qom University of Medical Sciences were selected. The ideal sample size was estimated based on the need for exploratory factor analysis. Assigning 5-10 participants to each item, a sample size of 400 was estimated (50 multiplied by 8 ) [14]. Considering the possible attrition, we planned to employ a sample of 452 caregivers from different units in the six hospitals. The demographic characteristics of participants including age, gender, work experience, employment status, marital status, and academic degree were also collected.

\section{Ethics}

The ethics committee of Tarbiat Modares University approved the study. All participants gave informed written consent.

\section{Results}

In all, 452 caregivers participated in the study, including 289 male (63.9\%) and 163 female (36.6\%) participants. The mean age of the participants was 37.71 (standard deviation $[S D]=8.3$ ) years, and their mean work experience was $10.27(\mathrm{SD}=8.1)$ years. The demographic characteristics of the participants are shown in the Table 1.

\section{Exploratory factor analysis}

The Kaiser-Meyer-Olkin measure was 0.85 , which falls in the "very good" category. The Bartlett's test of sphericity was significant (chi-square of 9739.127, $p<0.001$ ) indicating adequacy of the samples for the explorative factor analysis. The initial analysis indicated a seven-factor structure for the questionnaire. Ten items did not load on any factors and were thus removed. A final 40-item questionnaire loaded in seven distinct groupings. Table 2 shows six concepts derived from principle factor analysis with Varimax rotation for the MWRLBPPQ (Table 2).

\section{Reliability test}

The internal consistency of the MWRLBPPQ, as assessed by the Cronbach's a coefficient, showed satisfactory results with alpha ranging from 0.75 to 0.85 for each concept and 0.83 for the entire questionnaire. The ICC of the MWRLBPPQ also was found to be satisfactory, indicating that the questionnaire had good stability. The five-part Likert scale (from score 1 meaning "totally agree" to score 5 meaning "totally disagree" was used for all items. A total of 10 items were omitted, and the 40-item questionnaire was finally approved. The results of the reliability test as well as the score range for each concept are found in Table 1.

\section{Discussion}

According to the findings, satisfactory psychometric properties for the instrument with 7 factors and 40 state- 
Table 1. The characteristics of the study sample

\begin{tabular}{|c|c|c|}
\hline Demographic variable & EFA sample ( $\mathrm{n}=452)$ & Test-retest sample ( $\mathrm{n}=\mathbf{2 8}$ ) \\
\hline Age (yr) & $37(8.3)$ & $38.8(8)$ \\
\hline Work experience (yr) & $10.27(8.1)$ & $11.8(8.7)$ \\
\hline \multicolumn{3}{|l|}{ Sex } \\
\hline Male & 289 (63.9) & $22(78.6)$ \\
\hline Female & $163(36.6)$ & $6(21.4)$ \\
\hline \multicolumn{3}{|l|}{ Employment status } \\
\hline Official & $31(7)$ & - \\
\hline Official demo & $16(3.5)$ & $3(15)$ \\
\hline Contractual & $366(81)$ & $9(45)$ \\
\hline Other cases & $22(4.7)$ & $2(10)$ \\
\hline \multicolumn{3}{|l|}{ Marital status } \\
\hline Single & $47(10.4)$ & $3(10.7)$ \\
\hline Married & 391 (86.5) & $24(85.7)$ \\
\hline Divorced/widow & $14(3.1)$ & $1(3.6)$ \\
\hline \multicolumn{3}{|l|}{ Degree in nursing } \\
\hline Bachelor' degree & $58(12.8)$ & $1(3.6)$ \\
\hline Associate's degree & $14(3.1)$ & 0 \\
\hline Diploma degree & $112(24.8)$ & $12(42.9)$ \\
\hline Secondary degree & $113(25)$ & $3(10.7)$ \\
\hline Elementary degree & $138(30.5)$ & 12 (42.9) \\
\hline
\end{tabular}

EFA, exploratory factor analyses.

ments based on the SCT were achieved. Since CLBP in Iran is a prevalent problem among healthcare workers, the development of a multi-dimensional questionnaire which deals with low back pain that may stem from sociological, physical and psychological causes is necessary as it may promote attention to interventions that promote health and quality of life. The primary instrument was developed based on the SCT and the bio-psychosocial characteristics of nursing professionals with low back pain. Results from this research and existing literature led to the development of a nine-concept model, which we tested on a large sample of patient-care workers who provided patient-care lifting and transferring in hospitals. In our study, we asked them factors, as framed in the SCT, which might influence their low back pain.

In the present study, explanatory factor analysis showed satisfactory loading for the concept of self-efficacy, which is defined as a person's confidence in a particular behavior and in overcoming barriers to that behavior. Sharma believed that using persuasion and reinforcement in overcoming work barriers at work centers promotes self- efficacy [22]. This result indicated that Iranian patientcare workers believed that their low back pain was closely related to their self-efficacy, and they need to increase selfefficacy to prevent or reduce low back pain. Increasing self-efficacy was a common mechanism to achieve changes in behavior [12]. Efficacy beliefs play a central role in the self-regulation of motivation through goal challenges and an individual's outcome expectations [23].

Another concept that gained satisfactory loading was knowledge. This concept referred to learning facts and gaining insights related to an action, idea, object, person, or situation. This result indicated that Iranian patientcare providers believed that they should learn healthy behaviors to control and prevent low back pain. A previous study indicated that observational learning may contribute to development and maintenance of pain-related beliefs that lead to healthy behaviors [24].

There were different indicators describing the two separate concepts of outcome expectation and outcome expectancies in the primary questionnaire. According to our testing of psychometric properties, outcome expectation 
Table 2. Seven concepts derived from principle factor analysis with varimax rotation

\begin{tabular}{|c|c|}
\hline 1. Self efficacy: Score range (7-35) & Loadings \\
\hline 24) I have enough self-confidence in dealing with problem in my working environment. & 0.586 \\
\hline 26) I will do my best to control behaviors which are harmful to my lower back. & 0.657 \\
\hline $\begin{array}{l}\text { 27) When I decide to carry out behaviors which prevent lower back pain in my working environment, I seriously } \\
\text { concentrate on carrying out that behavior. }\end{array}$ & 0.694 \\
\hline 28) Even if the behaviors preventing lower back pain are time-consuming, I will carry them out. & 0.724 \\
\hline $\begin{array}{l}\text { 29) Even if some unexpected problems arise in the working environment, I will carry out the behaviors which prevent } \\
\text { lower back pain. }\end{array}$ & 0.699 \\
\hline $\begin{array}{l}\text { 30) If I do not have the skills necessary for carrying out the behaviors preventing lower back pain, I will try to gain } \\
\text { the skills. }\end{array}$ & 0.675 \\
\hline 31) I have confidence in my ability to avoid behaviors which are harmful to lower back in the working environment. & 0.681 \\
\hline Cronbach's alpha & 0.85 \\
\hline Eigen values & 9.613 \\
\hline Explained variance (\%) & 19.226 \\
\hline 2. knowledge: Score range $(8-40)$ & Loadings \\
\hline 1) If I learn from my colleagues to transfer a patient correctly, I will do it. & 0.703 \\
\hline $\begin{array}{l}\text { 2) If I learn from my colleagues to keep a correct lower back posture (while sitting, standing and lifting heavy weights), } \\
\text { I will do it. }\end{array}$ & 0.800 \\
\hline 3) If I learn from my colleagues to do useful lower back exercises, I will do them. & 0.748 \\
\hline 6) If I do exercises useful for my lower back, my lower back pain will decrease. & 0.593 \\
\hline 7) If I do exercises useful for my lower back, my physical ability will improve. & 0.639 \\
\hline 8) If I keep a correct backbone posture while working in the working environment, my lower back pain will decrease. & 0.568 \\
\hline 9) Controlling behaviors harmful to lower back in the working environment reduces lower back pain. & 0.550 \\
\hline 10) Controlling behaviors harmful to lower back in the working environment improves physical ability. & 0.522 \\
\hline Cronbach's alpha & 0.84 \\
\hline Eigen values & 3.799 \\
\hline Explained variance $(\%)$ & 7.598 \\
\hline 3. Outcome perception: Score range (8-40) & Loadings \\
\hline 11) Reduction in lower back pain after carrying out correct behaviors helps reduce my medical expenses. & 0.560 \\
\hline $\begin{array}{l}\text { 12) Reduction in lower back pain after carrying out correct behaviors helps reduce absence from the working } \\
\text { environment. }\end{array}$ & 0.527 \\
\hline 13) Increase in physical ability as a result of correct behaviors increases my efficiency in the working environment. & 0.616 \\
\hline 14) I try to understand the ways of preventing lower back pain. & 0.645 \\
\hline 15) I try to attract the attention of authorities to the ways of preventing lower back pain in the working environment. & 0.702 \\
\hline 16) I try to understand how can I prevent back pain with the existing environmental conditions. & 0.628 \\
\hline 17) Before fulfilling any duty in the working environment, I pay attention to my lower back posture. & 0.601 \\
\hline $\begin{array}{l}\text { 18) To improve my physical ability in the working environment, I think about all important behaviors for the prevention } \\
\text { of lower back pain. }\end{array}$ & 0.615 \\
\hline Cronbach's alpha & 0.84 \\
\hline Eigen values & 3.557 \\
\hline Explained Variance (\%) & 7.114 \\
\hline
\end{tabular}


Table 2. Continued

\begin{tabular}{|c|c|}
\hline 4. Self-control: Score range $(6-30)$ & Loadings \\
\hline 23) I am sure that I can do proper back exercise in my environment. & 0.520 \\
\hline $\begin{array}{l}\text { 38) I have the power to challenge colleagues and head nurses to remove the obstacles in the path of carrying out } \\
\text { behaviors which prevent lower back pain. }\end{array}$ & 0.603 \\
\hline 39) I often have plans for behaviors which prevent lower back pain in the working environment. & 0.595 \\
\hline 40) Before doing any activity in the working environment, I think about doing it with the correct posture. & 0.521 \\
\hline 41) While carrying out my duties in the working environment, I control the behaviors harmful to lower back. & 0.638 \\
\hline 42) In the working environment I try to pay attention to programs which prevent lower back pain. & 0.594 \\
\hline Cronbach's alpha & 0.78 \\
\hline Eigen values & 2.513 \\
\hline Explained variance $(\%)$ & 5.026 \\
\hline 5. Emotional coping: Score range (4-20) & Loadings \\
\hline 47) I feel pleased after doing special lower back exercises. & 0.807 \\
\hline 48) I feel satisfied that I control behaviors which are harmful to the lower back in the working environment. & 0.799 \\
\hline 49) It is easy for me to ask others for help with carrying out behaviors which prevent lower back pain. & 0.692 \\
\hline 50) Carrying out special lower back exercises makes me feel refreshed. & 0.817 \\
\hline Cronbach's alpha & 0.84 \\
\hline Eigen values & 1.963 \\
\hline Explained variance (\%) & 3.925 \\
\hline 6. Self-efficacy in overcoming impediments: Score range (4-20) & Loadings \\
\hline 33) While transferring patients, I try not to cause any injuries to the patient even if I cause an injury to myself. & 0.629 \\
\hline $\begin{array}{l}\text { 34) When the head nurse asks me to do something, I will do it instantly without caring about a proper lower back } \\
\text { posture. }\end{array}$ & 0.810 \\
\hline $\begin{array}{l}\text { 35) The fear of being reproached by colleagues or head nurse makes me carry out my duties without caring about } \\
\text { the proper behaviors which prevent lower back pain. }\end{array}$ & 0.755 \\
\hline 37) When I am required to carry out tasks above expectations even if I hurt my lower back. I feel pleased. & 0.551 \\
\hline Cronbach's alpha & 0.72 \\
\hline Eigen values & 1.908 \\
\hline Explained variance $(\%)$ & 3.816 \\
\hline 7. Environment: Score range (3-15) & Loadings \\
\hline 19) In my working environment, I carry out behaviors which prevent lower back pain. & 0.610 \\
\hline 22) I use the special exercise time for doing lower back exercise in my working environment. & 0.661 \\
\hline 46) I think the authorities pay a lot of attention to carrying out behaviors which prevent lower back pain. & 0.578 \\
\hline Cronbach's alpha & 0.57 \\
\hline Eigen values & 1.692 \\
\hline Explained variance (\%) & 3.383 \\
\hline Cumulative variance $(\%)$ & 50.088 \\
\hline Cronbach's alpha coefficient of the MSSCO & 0.83 \\
\hline
\end{tabular}

MSSCQ, multidimensional sexual self-concept questionnaire. 
is described as referring to anticipation of the probable outcomes that ensue as a result of engaging in a specific behavior [22] and are integrated within the knowledge concept. This shows that knowledge and outcome expectation are compatible and participants need to learn healthy behavior outcomes. Bandura identifies three types of outcomes including physical outcomes. These outcomes include positive and negative consequences of a particular behavior, social approval or disapproval of engaging or disengaging in the behavior, and positive and negative self-evaluation, and encouragement of individuals to participate in a specific behavior outcome expectancies, which is also described as value a person places on the probable outcomes that result from performing a behavior. These previously listed outcomes were grouped with situational perception and combined, they created one category named outcome perception. Situational perception is related to how patient-care providers perceive and interpret the environment around them [22].

Another concept derived from the explanatory factor analysis is self-control or goal setting and developing plans to accomplish a chosen behavior. Self-regulation is a key concept of the SCT that refers to skills individuals use to manage their behaviors. It is achieved through controlling oneself by self-monitoring, goal setting, feedback, self-reward, self-instruction, and enlisting social support [10]. This finding is similar to that of McAlister et al., stating that individuals control their behaviors through rewards and the planning and organization of environmental changes [10]. Self-control or self-regulation is one key construct of SCT [24] explored in the present study.

Emotional coping concept is the technique employed by a person to control the emotional and physiological states associated with acquisition of a new behavior, and is another concept that obtained satisfactory loading in this study. An additional concept that obtained satisfactory loading in this study is self-efficacy in overcoming impediments, which is defined as confidences that a person has in overcoming barriers while performing a given behavior. The last concept derived from explanatory factor analysis is environment. This refers to the physical or social circumstances or conditions that surround a person. Human behavior is shaped and controlled automatically and mechanically by environmental stimuli [23]. SCT hypothesizes that no amount of observational learning will lead to behavior change unless the observer's environment supports the new behaviors [25].
In this study, the nine concepts of the SCT were reduced to a seven-concept grouping. McAlister and co-workers verified that the nine concepts of the SCT could also be grouped into the five categories of psychological determinants, observational learning, environmental factors, selfregulation, and moral disengagement [10]. Exploratory factor analysis indicated that the structure of the questionnaire jointly accounted for $50 \%$ of the total variance observed.

Although the study benefits from several strengths, some limitations such as self-reporting of predicted factors should be considered. For instance, difficulty and anxiety in a work setting and long work hours may affect responses. However, despite these limitations, statisti$\mathrm{cal}$ analysis showed that this instrument had satisfactory statistical properties regarding measurement of low back pain predictors in nursing occupations in Iran.

\section{Conclusions}

The MWRLBPPQ is a reliable and valid theory-based instrument that can be used to predict the factors influencing work-related low back pain among patient-care workers.

\section{Conflict of Interest}

No potential conflict of interest relevant to this article was reported.

\section{Acknowledgements}

This study was part of the doctoral dissertation of the first author in health education and promotion at the Faculty of Medical Sciences, Tarbiat Modares University, and was approved by the institutional review board (IRB) of the university on June 30, 2014.

We thank the authorities and faculty members in the Medical School and Tarbiat Modares University. We also thank the Qom University of Medical Sciences authorities and staff in their assistance with the study.

\section{References}

1. Smith DR, Leggat PA. Musculoskeletal disorders among rural Australian nursing students. Aust J Rural Health 2004;12:241-5. 
2. Smedley J, Egger P, Cooper C, Coggon D. Manual handling activities and risk of low back pain in nurses. Occup Environ Med 1995;52:160-3.

3. Yip VY. New low back pain in nurses: work activities, work stress and sedentary lifestyle. J Adv Nurs 2004; 46:430-40.

4. Wilkinson WE, Salazar MK, Uhl JE, Koepsell TD, DeRoos RL, Long RJ. Occupational injuries: a study of health care workers at a northwestern health science center and teaching hospital. Aaohn J 1992;40: 287-93.

5. Retsas A, Pinikahana J. Manual handling activities and injuries among nurses: an Australian hospital study. J Adv Nurs 2000;31:875-83.

6. Punnett L, Wegman DH. Work-related musculoskeletal disorders: the epidemiologic evidence and the debate. J Electromyogr Kinesiol 2004;14:13-23.

7. Bagwell MM, Bush HA. Improving health promotion for blue-collar workers. J Nurs Care Qual 2000;14:6571.

8. Karahan A, Bayraktar N. Determination of the usage of body mechanics in clinical settings and the occurrence of low back pain in nurses. Int J Nurs Stud 2004;41:67-75.

9. Elder JP, Ayala GX, Harris S. Theories and intervention approaches to health-behavior change in primary care. Am J Prev Med 1999;17:275-84.

10. McAlister A, Perry C, Parcel G. How individuals, environments, and health behaviors interact,social cognitive theory. In: Glanz K, Rimer BK, Viswanath $\mathrm{K}$, editors. Health behavior and health education: theory, research and practice. San Francisco: JosseyBass; 2008. p.169-78.

11. Bandura A. Social learning theory. Englewood Cliffs: Prentice Hall; 1977.

12. Bandura A. Social foundations of thought and action: a social cognitive theory. Englewood Cliffs: PrenticeHall; 1986.
13. Tavafian SS, Jamshidi AR, Mohammad K. Treatment of chronic low back pain: a randomized clinical trial comparing multidisciplinary group-based rehabilitation program and oral drug treatment with oral drug treatment alone. Clin J Pain 2011;27:811-8.

14. Hajizadeh E, Asghari M. Statistical methods and analyses in health and biosciences: a methodological approach. Tehran: ACECR Press; 2011.

15. Lawshe $\mathrm{CH}$. A quantitative approach to content validity. Pers Psychol 1975;28:563-75.

16. Nunnally JC, Bernstein IH. Psychometric theory. New York: McGraw-Hill; 1994.

17. Auquier P, Pernoud N, Bruder N, et al. Development and validation of a perioperative satisfaction questionnaire. Anesthesiology 2005;102:1116-23.

18. Harrington D. Confirmatory factor analysis. Oxford: Oxford University Press; 2009.

19. Hyrkas K, Appelqvist-Schmidlechner K, Oksa L. Validating an instrument for clinical supervision using an expert panel. Int J Nurs Stud 2003;40:619-25.

20. Munro BH. Statistical methods for health care research. Philadelphia: Lippincott Williams \& Wilkins; 2005.

21. Norusis MJ. SPSS 16.0 statistical procedures companion. Upper Saddle River: Prentice Hall; 2008.

22. Sharma M, Romas JA. Theoretical foundations of health education and health promotion. Sudbury: Jones \& Bartlett Learning; 2012.

23. Bandura A. Social cognitive theory: an agentic perspective. Annu Rev Psychol 2001;52:1-26.

24. Trost Z, France CR, Vervoort T, Lange JM, Goubert L. Learning about pain through observation: the role of pain-related fear. J Behav Med 2014;37:257-65.

25. Bandura A. Social cognitive theory of mass communications. In: Bryant J, Zillmann D, editors. Media effects: advances in theory and research. Mahwah: Lawrence Elbaum Associates; 2002. p.121-53. 